\title{
Generation of Dose Volume Histograms Using Voxel Structure and the Monte Carlo Method in Low Dose Rate Brachytherapy
}

\section{Artur F. Menezes ${ }^{1}$, Hidmer Laulate1, Juraci P. Reis Junior ${ }^{1}$, Lucia H. Bardella², Alessandro Facure ${ }^{3}$, Ademir X. Silva ${ }^{1}$}

${ }^{1}$ Programa de Engenharia Nuclear/COPPE, Universidade Federal do Rio de Janeiro, Rio de Janeiro, Brasil

${ }^{2}$ Seção de Física Médica, Instituto Nacional de câncer, Rio de Janeiro, Brasil

${ }^{3}$ Comissão Nacional de Energia Nuclear, Rio de Janeiro, Brasil

Email: *arturfismed@gmail.com

How to cite this paper: Menezes, A.F., Laulate, H., Junior, J.P.R., Bardella, L.H., Facure, A. and Silva, A.X. (2016) Generation of Dose Volume Histograms Using Voxel Structure and the Monte Carlo Method in Low Dose Rate Brachytherapy. Internationa Journal of Medical Physics, Clinical Engineering and Radiation Oncology, 5, 230-241. http://dx.doi.org/10.4236/ijmpcero.2016.54024

Received: July 27, 2016

Accepted: October 24, 2016

Published: October 27, 2016

Copyright $\odot 2016$ by authors and Scientific Research Publishing Inc. This work is licensed under the Creative Commons Attribution International License (CC BY 4.0).

http://creativecommons.org/licenses/by/4.0/

\section{(c) (i) Open Access}

\begin{abstract}
The Dose Volume Histograms are tools commonly used in medical physics, for the analysis of doses delivered to the tumors and organs at risk, during radiotherapy treatments. However, there are few studies in the literature showing in details the steps of its construction. This work presents the implementation and evaluation of a computational methodology, for the construction of Dose Volume histograms, generated from simulations using anthropomorphic and voxel phantoms, in conjunction with the Monte Carlo code MCNP. The methodology was evaluated considering brachytherapy planning of low dose rate, using 108 seeds of I-125 with individual activities of $0.33 \mathrm{mCi}$ performed on the simulator in voxel recommended by ICRP 110 . The dosimetric analysis after implantation showed that the prostate received doses ranging from 0 to $360 \mathrm{~Gy}$. We found the values of 50, 145 and $160 \mathrm{~Gy}$ for the parameters $\mathrm{D}_{100}, \mathrm{D}_{90}$ and $\mathrm{D}_{80}$ and $28 \%, 90 \%, 92 \%$ and $95 \%$ for the parameters $\mathrm{V}_{200}, \mathrm{~V}_{100}$, $\mathrm{V}_{90}$ and $\mathrm{V}_{80}$. The rectum and bladder received maximum doses equal to 41 and $60 \mathrm{~Gy}$ and found the values of 39 and $22 \mathrm{~Gy}$ and 58 and $42 \mathrm{~Gy}$ to the parameters $\mathrm{D}_{0.1 \mathrm{ccc}}$ and $\mathrm{D}_{2 \mathrm{cc}}$, respectively. The results after dosimetric implant proved satisfactory, which validate the methodology described above.
\end{abstract}

\section{Keywords}

DVHs, Voxel, ICRP 110, MCNPX

\section{Introduction}

Today, the Monte Carlo method has become a tool commonly used in various segments 
of science and engineering to simulate problems that can be represented by stochastic processes, like simulations involving the transport of radiation applied to medical physics [1] [2]. These codes can be used for photon, electron and neutron transport and can be applied to radiation protection and dosimetry, radiation shielding, medical physics among other areas [3].

The use of the Monte Carlo method, in conjunction with voxels phantoms made possible the reproduction of some radiotherapy treatment planning in computing environments, simulating more realistic scenarios of the different structures of the human body. In this sense, for performing simulation involving the Monte Carlo method it is necessary to use voxel structure recognized by the MCNP radiation transport code. For this purpose, Boia et al. [4] developed a computational methodology to convert the patient DICOM image in a voxel structure recognized by MCNP code. Alternatively, there are studies [5] using voxel simulator MAX and others [6] using REX simulator published by Kramer et al. [7] and for the ICRP110 [8], respectively.

For the analysis of the doses tools called Dose Volume Histograms (DVHs) have been used that are tools made available by different radiotherapy treatment planning systems, which are used to assess the radiation dose for each specific volume, and represent the frequency distribution of the dose values obtained in a three-dimensional voxel matrix, even for the target volume or to the critical adjacent structures [9].

Studies related to DVHs have been conducted by some researchers considering different methodologies. Pyakuryal et al. [10] developed a MatLab program to analyze plans of exported doses of Pinacco treatment planning system. Bruno et al. [11] conducted a dosimetric comparative study of implants using I-125 and Pd-103 sources based on the analyses of the DVHs in conjunction with SISCODES program (Computer System for Dosimetry by Neutrons and Photons by Stochastic Methodos) and MCNP code.

Although there are studies in the literature reporting the use of the dose volume histogram (DVHs), it can be seen that there is a lack of detail showing how these tools are built through simulation treatments using in voxels simulators and MCNP transport code. In this context, the application of a computational methodology will assist users in the construction of the DVHs, from simulations using anthropomorphic phantoms in voxels and the Monte Carlo method is justified. For this purpose, we used the MCNPX code to obtain a digital output file, with the dosimetric data to be evaluated, enabling the construction of Dose Volumes Histograms for organs that are the objects of this study considering an implant of low dose rate brachytherapy using ${ }^{125} \mathrm{I}$ sources.

\section{Methodology}

\subsection{Modeling and Validation of I-125 Source}

The first step in this work consisted in to model and validate a brachytherapy source containing ${ }^{125} \mathrm{I}$, Amersham, model 6711 [12].

The validation was performed by the evaluation of the parameters dose rate constant, 
anisotropy function and radial dose function, recommended by the dosimetry protocol TG43U1 [13]. This source is constituted by two cylinders, the inner is composed of silver, $\rho=10.5 \mathrm{~g} / \mathrm{cm}^{3}$, and has a length of $3 \mathrm{~mm}$ and basis of $0.5 \mathrm{~mm}$ coated by an emmiter thickness of $1 \mu \mathrm{m}$, containing ${ }^{125} \mathrm{I}$ in the form of silver iodide $\left(\rho=6.2 \mathrm{~g} / \mathrm{cm}^{3}\right)$. The outer cylinder is composed of titanium $\left(\rho=4.54 \mathrm{~g} / \mathrm{cm}^{3}\right)$, has a length of $4.5 \mathrm{~mm}$ and basis of $0.81 \mathrm{~mm}$ closed by two ellipsoides [12]. The energy distribution of the photons emitted by the simulated ${ }^{125} \mathrm{I}$ source, used as an input parameter for the simulation, is presented in Table 1 .

\subsection{Dose Volume Histogram (DVH)}

For the generation and evaluation of the DVHs using the MCNP Monte Carlo code, a prostate treatment plan consisting of $108{ }^{125}$ I seeds was elaborated, with seed activities of $0.33 \mathrm{mCi}$, using the male phantom model recommended by ICRP110 [8]. Considering that the prostate of the simulator has very small volume, the seeds were inserted with spacing of $5 \mathrm{~mm}$.

Figure 1 shows the mentioned model, that represents an adult of 38 years, with a height of $176 \mathrm{~cm}$ and weight of about $73 \mathrm{~kg}$. This simulator has voxels dimension of $2.137 \times 2.137 \times 8 \mathrm{~mm}^{3}$, which corresponds to a volume equal to $36.53 \mathrm{~mm}^{3}$ and contains a total of 122 segmented structures.

The distribution of the ${ }^{125}$ I seeds inside the prostate was obtained using the automatic replication program developed by Boia et al. [14]. The dose in each voxel of interest was obtained setting some plans, in order to define volumetrically the volume of each organ and using the MCNP code tools, that allow the individual calculation of the dose for all voxels delimited by the plans.

The absorbed dose in the volume studied was obtained using the command tally ${ }^{*} F 8$ $(\mathrm{MeV})$ of the MCNP code, applied in each voxel of interest, considering the number $(\mathrm{N})$ of the used sources divided by the mass $(\mathrm{g}$ ) of each voxel, taking in account the integration of the activity throughout the life of the source (Equation (1)). All simulations were performed considering the transport of photons and electrons (mode p e) with a cutoff energy of $5 \mathrm{keV}$ and the dose of the prostate, bladder and rectum were evaluated using the methodology described above.

Table 1. Energy distribution of the fotons emitted by ${ }^{125}$ I sources [12].

\begin{tabular}{cc}
\hline Energy $(\mathrm{MeV})$ & Photons per disintegration \\
\hline 0.035492 & 0.0668 \\
0.03171 & 0.0439 \\
0.03098 & 0.202 \\
0.027472 & 0.757 \\
0.027202 & 0.406 \\
Total & 1.4757 \\
\hline
\end{tabular}




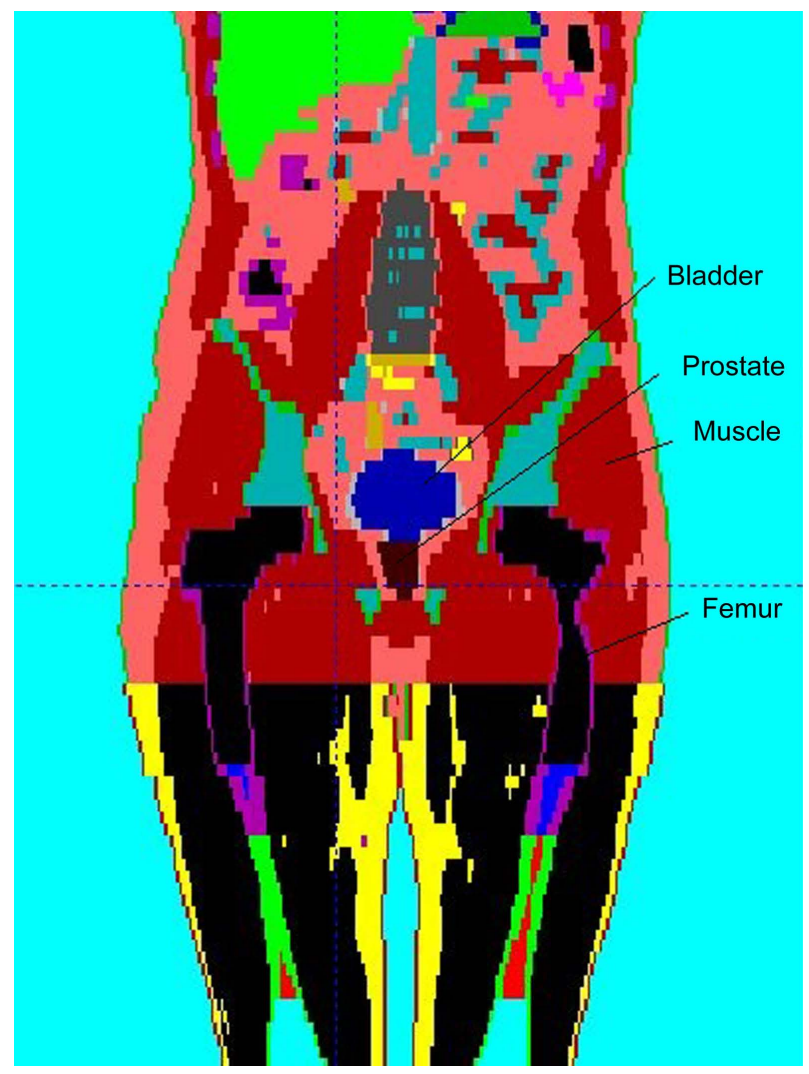

Figure 1. Visualization of the different structures present in the male anthropomorphic simulator, recommended by ICRP110.

$$
D(\mathrm{~Gy})=1.602 \times 10^{-10}(N)\left(\frac{A_{0}}{\lambda}\right)\left(\frac{F 8(\mathrm{MeV})}{m(\mathrm{~g})}\right)
$$

Through the analysis of the doses obtained for all voxels in the organ of interest, it became possible to generate the Dose Volume Histogram, taking into account the class interval for the desired dose level and the frequency distribution of voxels for these dose levels. The simulation was performed using the MCNPX code, with uncertainties below $5 \%$, thus guaranteeing satisfactory results according to the limits of reliability presented by the relative error interpretation guidelines of MCNP like can be seen in Table 2 [15].

Figure 2 illustrates the computational diagram of the metotology for DVHs generation using the MCNP radiation transport code applied to Low Dose Rate Brachytherapy implant using ${ }^{125}$ I sources.

\section{Results and Discussion}

\subsection{Computational Modeling and Validation of 125I Source}

Figure 3 shows two-dimensional cuts, obtained with the Moritz graphic viewer [16] illustrating the shape of different structures constituting the simulated ${ }^{125} \mathrm{I}$ source. The titanium encapsulation and silver cylinder of the ${ }^{125} \mathrm{I}$ sources are illustrated. The use of 
Table 2. Guidelines for interpretation of the relative errors (R) obtained for MCNP [15].

\begin{tabular}{cc}
\hline Range of R & Tally Quality \\
\hline $0.5-1.0$ & Not Reliable \\
$0.2-0.5$ & Hardly Reliable \\
$0.1-0.2$ & Questionably \\
$<0.1$ & Generally Reliable \\
$<0.05$ & Reliable \\
\hline
\end{tabular}

Step 1
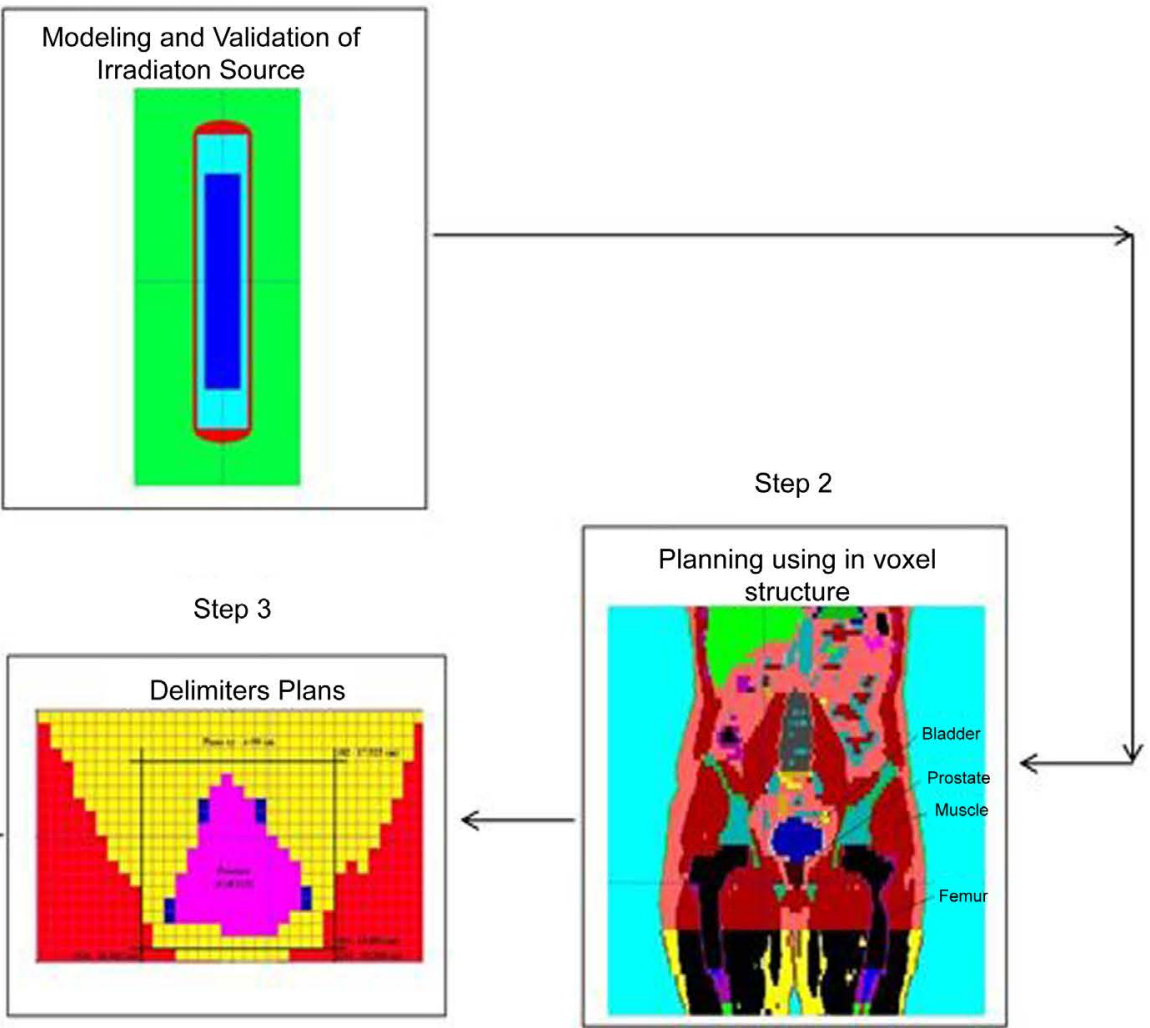

Step 3

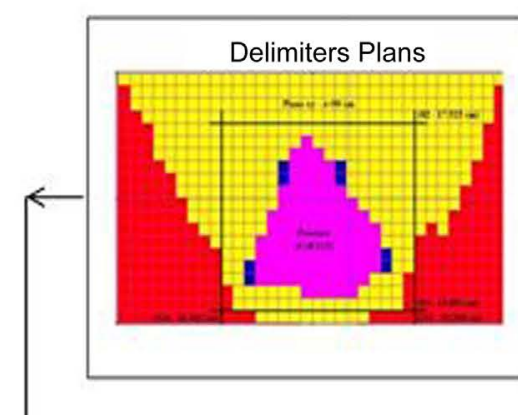

Step 4

Step 5
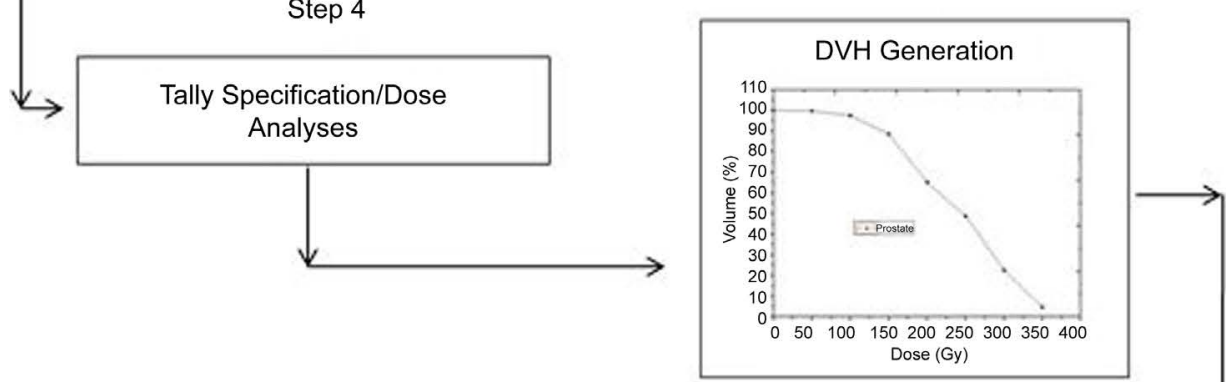

Step 6

Pos Implant Analyses

Figure 2. Diagram of the computational methodology for the generation of Dose Volume Histograms. 


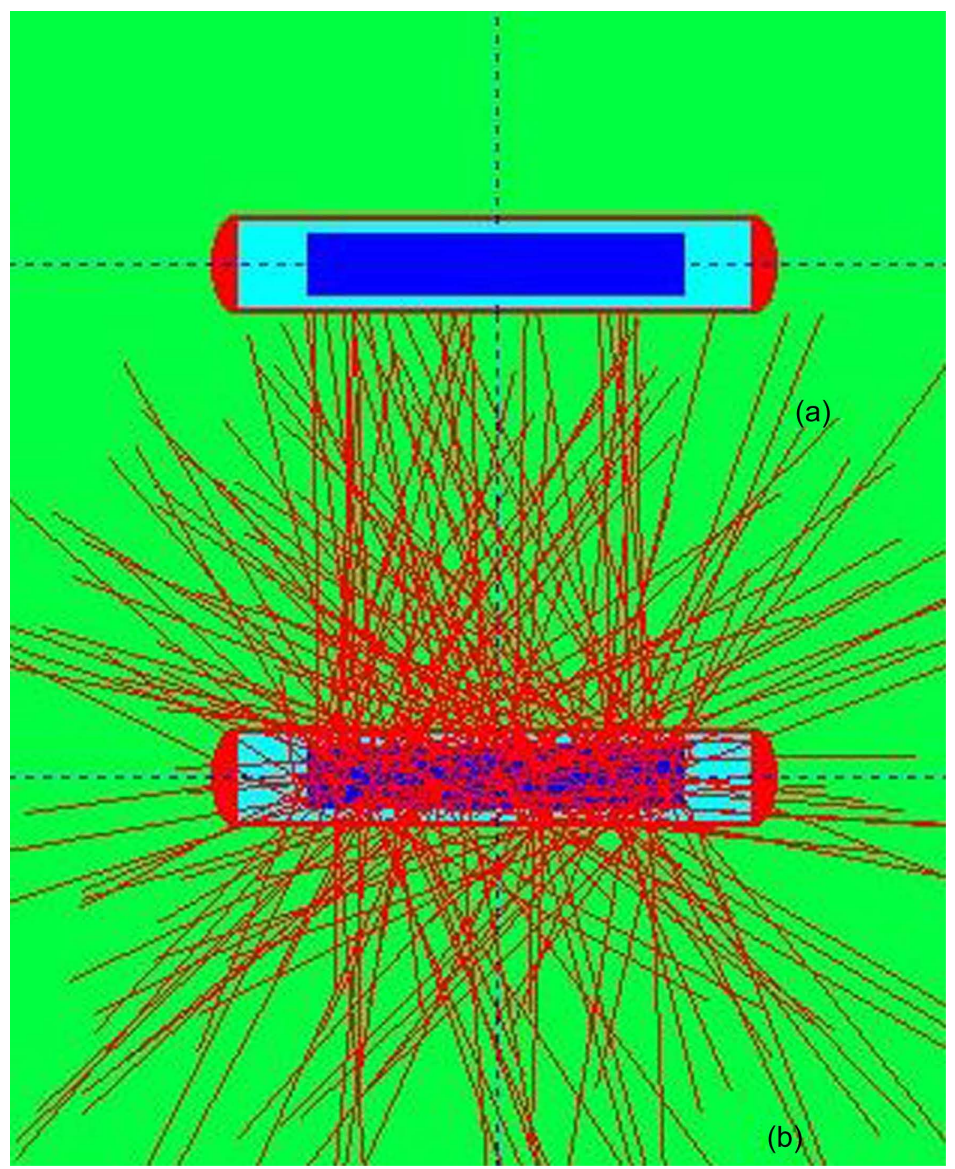

Figure 3. ${ }^{125}$ I sources modeled using MCNP code: (a) Two-dimensional view; (b) Photons emitted by the source.

the ptrack card, provided by the MCNP code, permitted the illustration of the particle being emitted by modeled sources in the Figure 3(b).

Table 3 shows the results obtained in this work for the dose rate constant, in comparison with the results taken from the literature [17]-[19]. The good agreement is an indication of computational effectiveness of the performed modeling.

The results presented in this work (Table 3 ) showed a better agreement with those obtained in references [19]. It should be mentioned that the value associated with the TG-43 report is higher than those obtained in the other references, $4 \%$ higher when compared to the present work.

In Figure 4 the results for the anisotropy function are shown for $1 \mathrm{~cm}$ distance, compared with other workers results obtained from the literature [13] [18] [19]. It Can be seen a good agreement with the literature results.

Figure 5 is showed the result for the radial dose functions obtained for ${ }^{125} \mathrm{I}$. They are compared with the results of several studies reported in the literature [13] [18] [19]. It can be seen a good agreement with the literature results.

Based on the results obtained for dosimetric parameters it can be concluded that the I-125 irradiation source is validated and can be used for the next steps for this study. 
Table 3. Dose rate constant of ${ }^{125} \mathrm{I}$ source.

\begin{tabular}{cc}
\hline References & Dose Rate Constant (cGy/hU) \\
\hline TG-43 Consensus Value (Rivard et al.) [17] & 0.965 \\
J. Dolan et al. (extrap/WAFAC (PTRAN)) [18] & 0.942 \\
R. E. Taylor, D. W. O. Rogers (WAFAC) [19] & 0.924 \\
R. E. P. Taylor. D. W. Rogers (Point) [19] & 0.942 \\
This Study & 0.928 \\
\hline
\end{tabular}

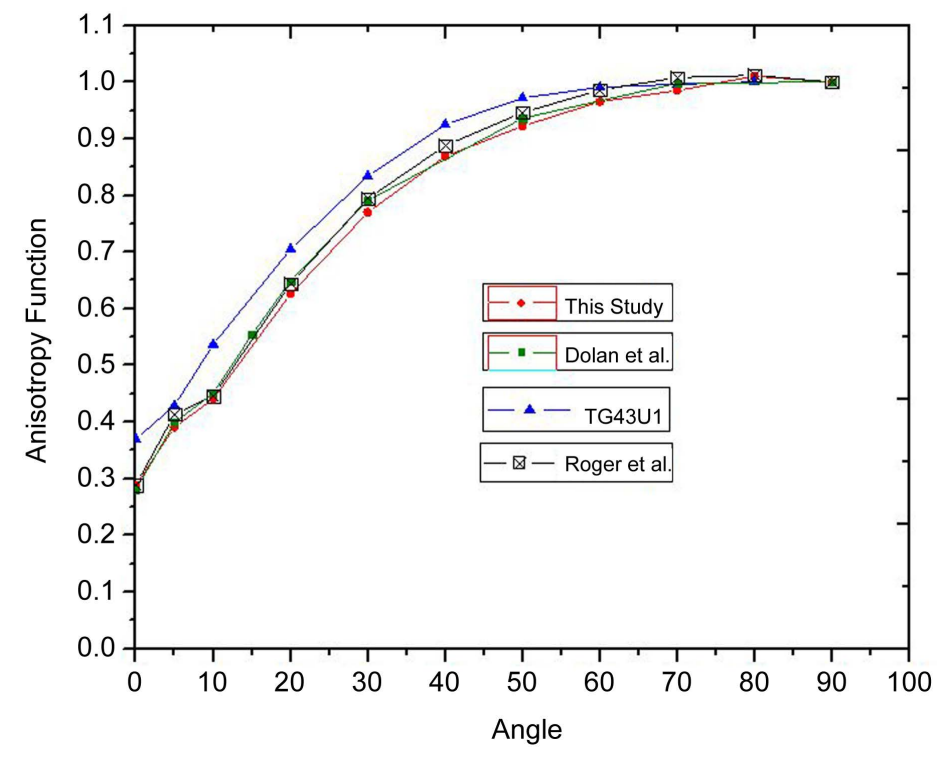

Figure 4. Anisotropy function from $1 \mathrm{~cm}$ irradiation source.

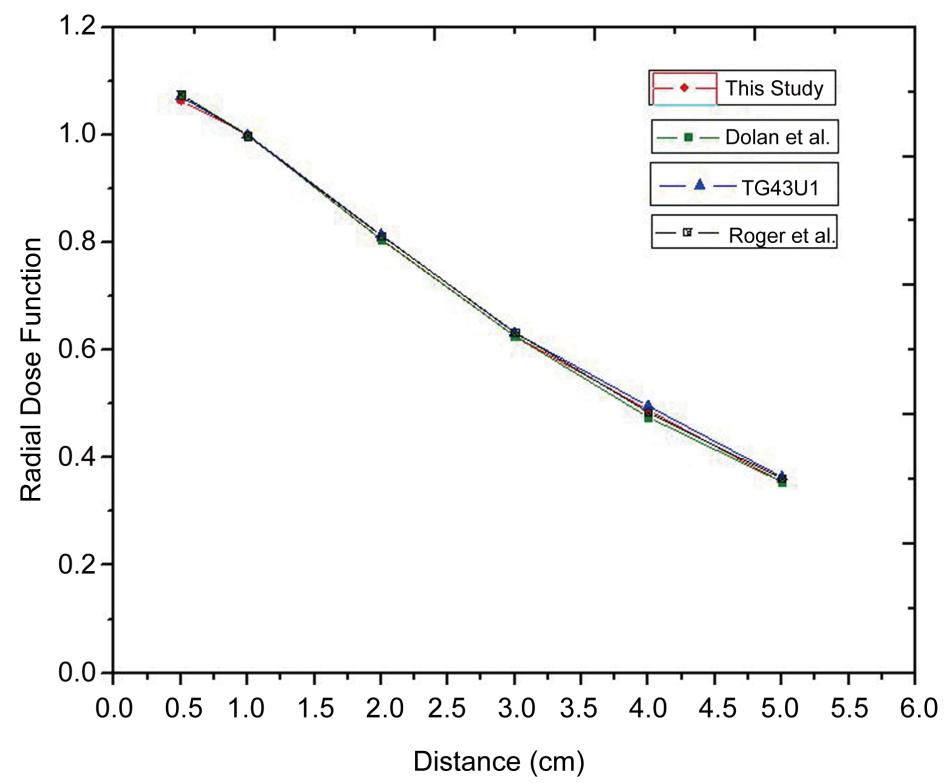

Figure 5. Radial dose function of I-125 source. 


\subsection{Dose Volume Histogram}

This section presents the DVHs results for the prostate, bladder and rectum using the methodology described above. In Table 4 the distributions of the Dose Volume Frequency are presented, considering all voxels of the prostate volume and intervals classes interval equal to $50 \mathrm{~Gy}$. The prostate gland received doses ranging between 0 and 360 Gy when 108 seeds of ${ }^{125} \mathrm{I}$ were simulated. The parameters $\mathrm{F}_{\mathrm{Vol}}, \mathrm{F}_{\mathrm{ac}}$, represent the volumetric and accumulated frequency, respectively. The volumetric frequency $\left(\mathrm{F}_{\mathrm{Vol}}\right)$ was obtained by multiplying the number of voxels belonging to a range of dose and the volume of individual voxel. The accumulated frequency $\left(\mathrm{F}_{\mathrm{ac}}\right)$ was obtained through the sum of the accumulated volumes to the levels of doses considered.

Figure 6 shows the DVH obtained through the distributions of frequency presented in Table 4. We found the values of 50, 145 and 160 Gy for parameters $D_{100}, D_{90}$ and $D_{80}$,

Table 4. Dose volume frequency for the prostate grand.

\begin{tabular}{cccccc}
\hline Classes (Gy) & Voxels/Classes & $\mathrm{F}_{\text {Vol }}\left(\mathrm{cm}^{3}\right)$ & Dose $(\mathrm{Gy})$ & $\mathrm{Fac}_{\text {ac }}\left(\mathrm{cm}^{3}\right)$ & Volume $(\%)$ \\
\hline $0-50$ & 1 & 0.04 & 350 & 0.77 & 4.7 \\
$50-100$ & 10 & 0.37 & 300 & 3.73 & 22.6 \\
$100-150$ & 41 & 1.50 & 250 & 8.04 & 48.8 \\
$150-200$ & 105 & 3.84 & 200 & 10.74 & 65.2 \\
$200-250$ & 74 & 2.70 & 150 & 14.58 & 88.5 \\
$250-300$ & 118 & 4.31 & 100 & 16.08 & 97.6 \\
$300-350$ & 81 & 2.96 & 50 & 16.44 & 99.8 \\
$350-400$ & 21 & 0.77 & 0 & 16.48 & 100 \\
Total & 451 & 16.48 & & & \\
\hline
\end{tabular}

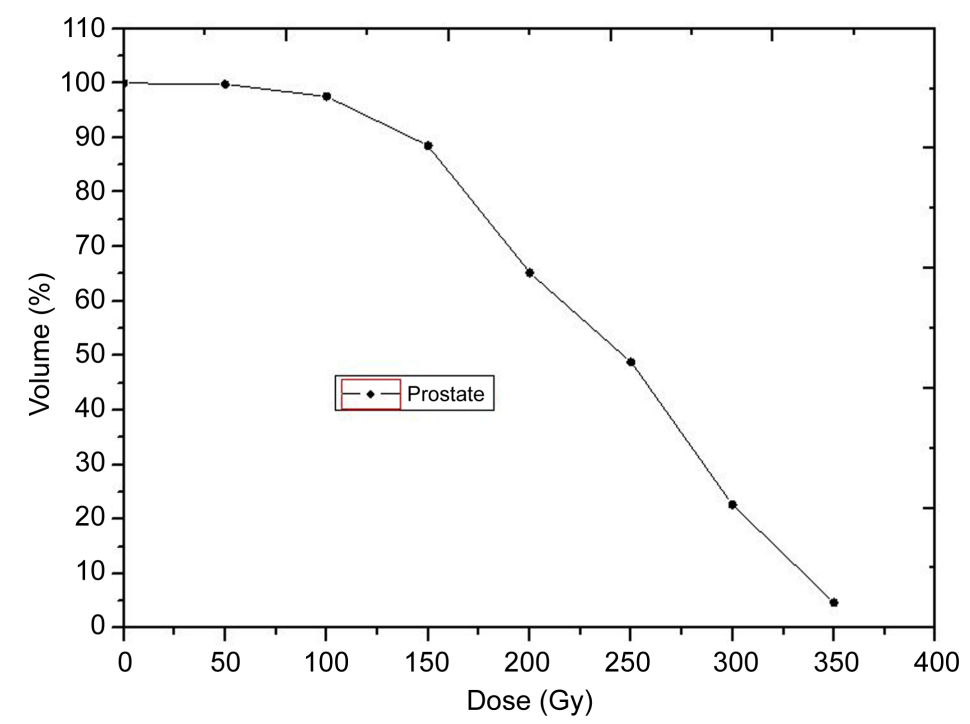

Figure 6. Dose volume histogram for the prostate gland. 
and $28 \%, 90 \%, 92 \%$ and $95 \%$ for volumetric parameters $\mathrm{V}_{200}, \mathrm{~V}_{100}, \mathrm{~V}_{90}$ and $\mathrm{V}_{80}$, respectively. The DVH shows that $90 \%$ of the volume of the prostate receives a value of dose equal to $145 \mathrm{~Gy}$, which is typically used as a reference [20]-[22] for the prescription dose in Low Dose Brachytherapy using ${ }^{125}$ I sources. Based on these dosimetric parameters the implant was considered satisfactory for the purpose of this study.

Figure 7 illustrates the DVHs for the rectum and bladder, using class intervals of 5 Gy. It can be seen that the rectum and bladder received maximum doses equal to 41 and $60 \mathrm{~Gy}$, respectively. The DVH show that 0.1 and $2 \mathrm{~cm}^{3}\left(\mathrm{D}_{0.1 \mathrm{cc}}\right.$ and $\left.\mathrm{D}_{2 \mathrm{cc}}\right)$ of the rectum received doses of 39 and $22 \mathrm{~Gy}$. The bladder received doses of 58 and 42 Gy in 0.1 and 2 $\mathrm{cm}^{3}$ of volume. These values are in agreement with reference values presented in the literature [20]-[22].

The isodose curves were obtained in a region of the prostate using the MCNP command mesh tally. The mesh tally was used to quantify the absorbed dose in a matrix of dose defined by voxels of dimensions $0.12 \times 0.12 \times 0.12 \mathrm{~cm}^{3}$.

The absorbed dose obtained for each voxel of the mesh tally array was recorded in a binary file. The values of doses were obtained primarily in rem/h and subsequently converted to Gy/s per particle emitted by the source. For the construction of the isodose curves a program in MATLAB was developed.

Figure 8 shows that the curve of 145 Gy was used as prescription cover all volumetric extension of the prostate gland.

\section{Conclusions}

The results generated to the DVHs applying the methodology adopted for the implan-

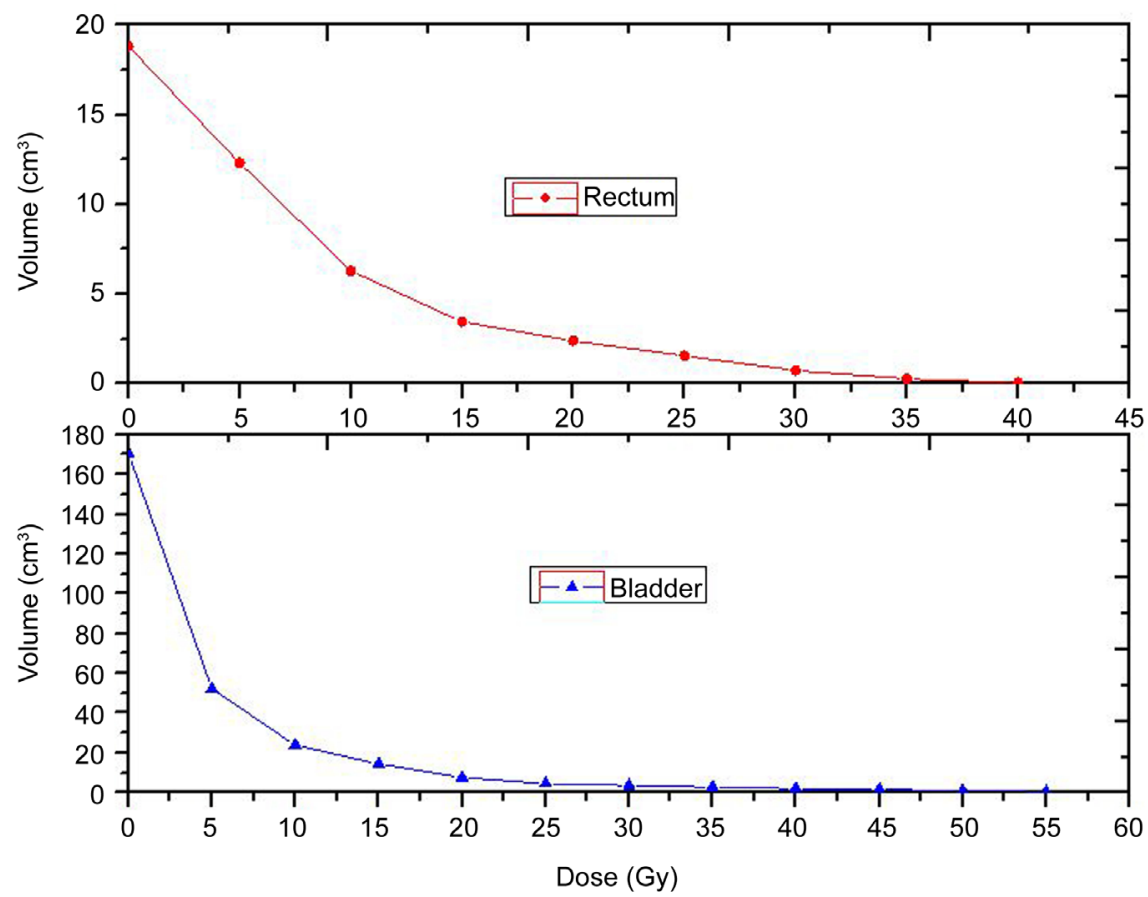

Figure 7. Dose volume histogram for the rectum and bladder. 


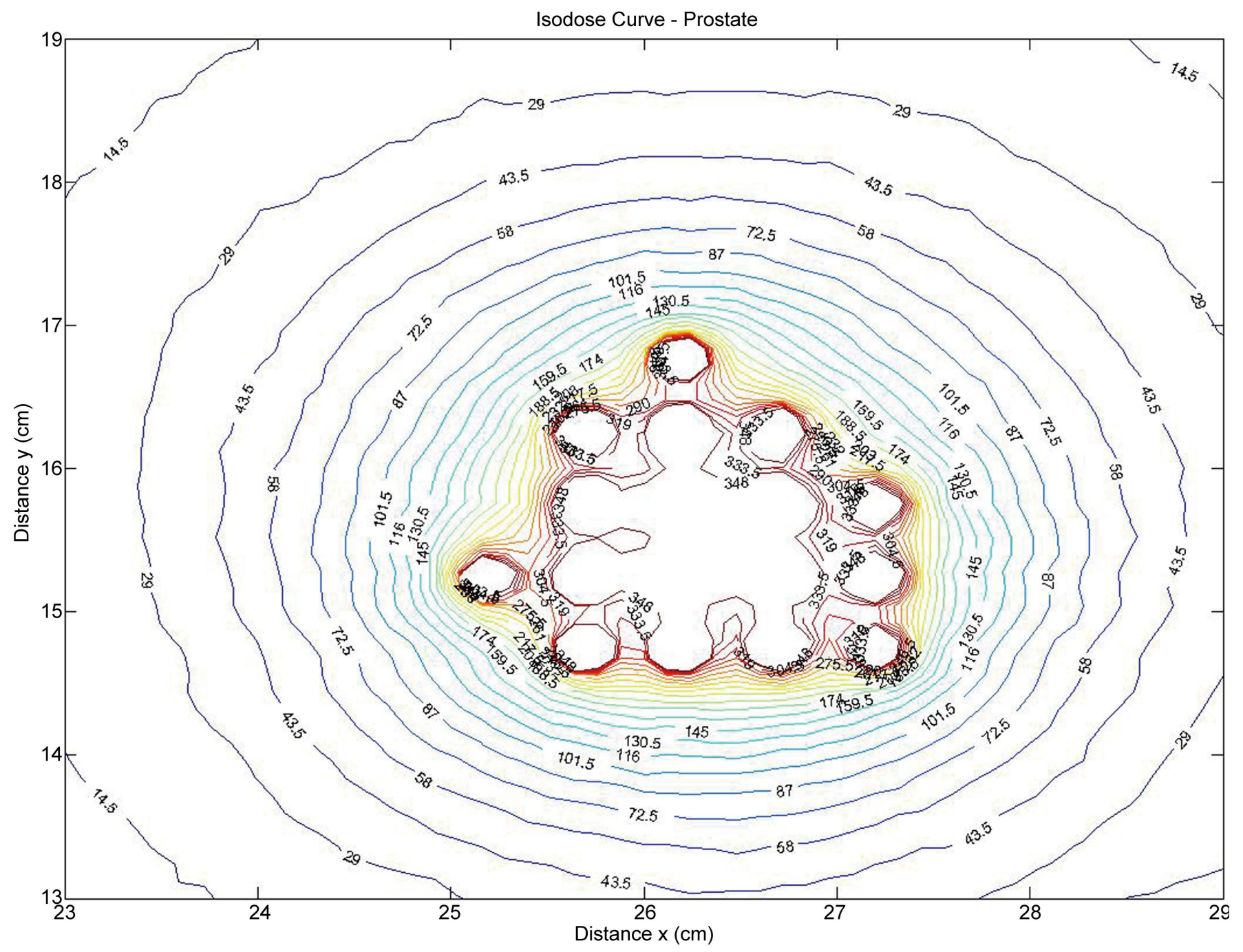

Figure 8. Isodose curves using the Matlab program.

tation of 108 seeds of ${ }^{125}$ I proved satisfactory for the assessment of doses in the prostate gland and in adjacent organs of males' anthropomorphic phantom of the ICRP.

The prostate gland received doses between 0 and $360 \mathrm{~Gy}$. We found the values of 50, 145 and $160 \mathrm{~Gy}$ for the parameters $\mathrm{D}_{100}, \mathrm{D}_{90}$ and $\mathrm{D}_{80}$ and $28 \%, 90 \%, 92 \%$ and $95 \%$ for the parameters $\mathrm{V}_{200}, \mathrm{~V}_{100}, \mathrm{~V}_{90}$ and $\mathrm{V}_{80}$.

The rectum and bladder received maximum doses equal to 41 and $60 \mathrm{~Gy}$ and found the values of 39 and $22 \mathrm{~Gy}$ and 58 and $42 \mathrm{~Gy}$ to the parameters $\mathrm{D}_{0.1 \mathrm{cc}}$ and $\mathrm{D}_{2 \mathrm{cc}}$, respectively.

Taking into account the results found for the prostate gland and for the adjacent organs, it was concluded that the implants present the requirements indicative of good quality for ${ }^{125} \mathrm{I}$ implants in treatment using Low Dose Rate brachytherapy. Given this fact, the methodology for the construction of Dose Volume Histogram using the MCNP radiation transport code and in voxel structure proved to be satisfactory for the purpose of this work. 
This methodology is not restricted to brachytherapy and can be used to construct Dose Volume Histogram using dose data file generated with external beam irradiation and patient DICOM image. Although it is necessary for the user to model and validate the irradiation source and convert the patient DICOM image in voxel structure file recognized by MCNP Monte Carlo Code. However, the user should only make comparative studies between DVHs generated by simulation and the respective obtained using treatment planning systems if it guarantees the same volumes for organs studied.

\section{Acknowledgements}

The authors wish to thank Cecilia Khalil Haddad and Tatiana Midori of SirioLibanes Hospital for the collaboration and the financial support of the Fundação Carlos Chagas Filho de Amparo à Pesquisa do Estado do Rio de Janeiro (FAPERJ), the Coordenação de Aperfeiçoamento de Pessoal de Nível Superior (CAPES) and the Conselho Nacional de Desenvolvimento Científico e Tecnológico (CNPQ), Brazil.

\section{References}

[1] Yoriyaz, H. (2009) Monte Carlo Method: Principles and Application in Medical Physics. Revista Brasileira de Física Médica, 3, 141-149.

[2] Reis Junior, J.P., Menezes, A.F., Souza, E.M., Facure, A. Medeiros, J.A.C. and Silva, A.X. (2012) Dose Optimization in ${ }^{125}$ I Permanent Seed Implants Using the Monte Carlo Method. Computer Physics Communications, 183, 847-852.

http://dx.doi.org/10.1016/j.cpc.2011.12.005

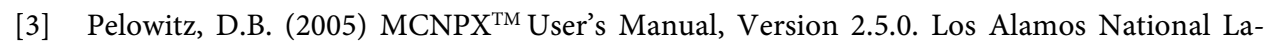
boratory Report LA-CP-05-0369.

[4] Boia, L.S., Menezes, A.F., Cardoso, M.A.C., et al. (2012) Application of Digital Image Processing for the Generation of Voxels Phantoms for Monte Carlo Simulation. Applied Radiation and Isotopes, 70, 144-148. http://dx.doi.org/10.1016/j.apradiso.2011.08.017

[5] Thalhofer, J.L., Rebello, W.F., Correa, S.C.A., Silva, A.X., Souza, E.M. and Batista, D.V.S. (2013) Calculation of Dose in Healthy Organs, during Radiotherapy 4-Field Box 3D Conformal for Prostate Cancer, Simulation of the Linac 2300, Radiotherapy Room and MAX Phantom. International Journal of Medical Physics, Clinical Engineering and Radiation Oncology, 2, 61-68. http://dx.doi.org/10.4236/ijmpcero.2013.22009

[6] Martins, M.C., Cordeiro, T.P.V., Silva, A.X., Souza-Santos, D., Queiroz-Filho, P.P. and Huant, J.G. (2013) Dose Conversion Coefficients for ICRP 110 Voxel Phantom in the Geant4 Monte Carlo Code. Radiation Physics and Chemistry, 95, 309-312. http://dx.doi.org/10.1016/j.radphyschem.2013.04.030

[7] Kramer, R., Vieira, J.W., Khoury, H.J., Lima, F.R.A. and Fuelle, D. (2003) All about MAX: A Male Adult Voxel Phantom for Monte Carlo Calculations in Radiation Protection Dosimetry. Physics in Medicine and Biology, 48, 1239-1262.

http://dx.doi.org/10.1088/0031-9155/48/10/301

[8] ICRP (2009) Adult Reference Computational Phantom. International Commission on Radiological Protection. Pergamon Press, Oxford.

[9] Drzymala, R.E., Mohan, R., Brewster, L., et al. (1991) Dose-Volume Histograms. International Journal of Radiation Oncology, Biology and Physics, 21, 71-78.

http://dx.doi.org/10.1016/0360-3016(91)90168-4 
[10] Pyakuryal, A., Myint, W.K., Gopalakrishnan, M., Jang, S., Logemann, J.A. and Mittal, B.B. (2010) A Computational Tool for the Efficient Analysis of Dose-Volume Histograms for Radiation Therapy Treatment Plans. Journal of Applied Clinical Medical Physics, 11, 30133041.

[11] Trinidade, B.M., Chistóvão, M.T., Trindade, D. de F.M., Falcão, P.L. and de Campos, T.P.R. (2012) Comparative Dosimetry of Prostate Brachytherapy with I-125 and Pd-103 Seeds via SISCODES/MCNP. Radiologia Brasileira, 45, 1443-1450.

[12] Duggan, D.M. (2004) Improved Radial Dose Function Estimation Using Current Version MCNP Monte-Carlo Simulation: Model 6711 and ISC3500 ${ }^{125}$ I Brachytherapy Sources. Applied Radiation and Isotopes, 61, 1443-1450. http://dx.doi.org/10.1016/j.apradiso.2004.05.070

[13] Rivard, M.J. (1999) Refinements to the Geometry Factor Used in the AAPM Task Group Report No. 43 Necessary for Brachytherapy Dosimetry Calculations. Medical Physics, 26, 2445-2450. http://dx.doi.org/10.1118/1.598764

[14] Boia, L.S., Junior, J.P.R., Menezes, A.F. and Silva, A.X. (2014) Computational System to Create an Entry File for Replicating I-125 Seeds Simulating Brachytherapy Case Studies Using the MCNPX Code. International Journal of Cancer Therapy and Oncology, 2, 24452450. http://dx.doi.org/10.14319/ijcto.0202.3

[15] Briesmeister, J.F. (1997) MCNP-A General Monte Carlo N-Particle Transporte Code, Version 4B. Report No. LA12625-M. Los Alamos National Laboratory, Los Alamos.

[16] Riper, K.A.V. (2004) MORITZ-Geometry Tool User' Guide. White Rock Science, Los Alamos.

[17] Rivard, M.J., Coursey, B.M., DeWerd, L.A., et al. (2004) Update of AAPM Task Group No. 43 Report: A Revised AAPM Protocol for Brachytherapy Dose Calculations. Medical Physics, 31, 633-674. http://dx.doi.org/10.1118/1.1646040

[18] Dolan, J., Li, Z. and Williamson, J.F. (2006) Monte Carlo and Experimental Dosimetry of an ${ }^{125} \mathrm{I}$ Brachytherapy Seed. Medical Physics, 33, 4675-4684.

http://dx.doi.org/10.1118/1.2388158

[19] Taylor, R.E.P. and Rogers, D.W.O. (2008) An EGSnrc Monte Carlo-Calculated Database of TG-43 Parameters. Medical Physics, 35, 4228-4242. http://dx.doi.org/10.1118/1.2965360

[20] Nath, R., Bice, W.S., Butler, W.M., et al. (2009) AAPM Recommendations on Dose Prescription and Reporting Methods for Permanent Interstitial Brachytherapy for Prostate Cancer: Report of the American Association of Physicists in Medicine Task Group 137. Medical Physics, 36, 5310-5322. 2445-2450.

[21] Marcu, L. and Quach, K. (2006) The Role of Post-Implant Dosimetry in the Quality Assessment of Prostate Implants. The RAH Experience. Australasian Physical and Engineering Science in Medicine, 29, 310-314. http://dx.doi.org/10.1007/BF03178396

[22] Yu, Y, Anderson, L.L., Li, Z., et al. (1999) Permanent Prostate Seed Implant Brachytherapy: Report of the American Association of Physicists in Medicine Task Group No. 64. Medical Physics, 26, 2054-2076. http://dx.doi.org/10.1118/1.598721 
Submit or recommend next manuscript to SCIRP and we will provide best service for you:

Accepting pre-submission inquiries through Email, Facebook, LinkedIn, Twitter, etc.

A wide selection of journals (inclusive of 9 subjects, more than 200 journals)

Providing 24-hour high-quality service

User-friendly online submission system

Fair and swift peer-review system

Efficient typesetting and proofreading procedure

Display of the result of downloads and visits, as well as the number of cited articles

Maximum dissemination of your research work

Submit your manuscript at: http://papersubmission.scirp.org/

Or contact ijmpcero@scirp.org 